\title{
Qualitative Content Analysis of Activity Theory, Situated Learning and Cognitive Tools and Introducing an Integrated and Conceptual Model
}

\author{
Hashem Fardanesh, ${ }^{1}$ and Maede Maleki ${ }^{2,}{ }^{*}$ \\ ${ }^{1}$ Department of Education Faculty, University of Tarbiat Modares, IR Iran \\ ${ }^{2}$ University of Tarbiat Modares, IR Iran \\ "Corresponding author: Maede Maleki, PhD Student of Instructional Technology, University of Tarbiat Modares, IR Iran. E-mail: maede.maleki@yahoo.com
}

Received 2016 October 30; Accepted 2016 December 24.

\begin{abstract}
Introduction: The aim of this research was to qualitatively analyze the teaching and learning components of socio-cultural constructivism theories such as activity theory, situated learning and cognitive tools and provide a model along with workable examples that can be used by designers, educational experts, and teachers.

Methods: The method of this study was qualitative content analysis. The study was conducted in 2015. Statistical population was all documents, articles, posts, and reviews written during 1991 - 2014 (100 sources) related to the 3 theories of this study. The content of these resources were selected and analyzed using the purposive sampling method, which extracted categories and sub-categories of documents. Finally, the main components were coded and the conceptual model was developed based on research findings.

Results: Results of the analysis led to the identification of the components of the integrated and conceptual model. The model consisted of 2 phases that include, analysis of community of practice and designing learning environment that include analysis of tool, analysis of learner, analysis of activity, and several common factors that support all of the learning environment.

Conclusions: This article introduced a conceptual model for designing of situated learning, activity, and cognitive tools. It may be used in face-to-face, online, and combined environments.
\end{abstract}

Keywords: Instructional Design, Activity Theory, Situated Learning, Cognitive Tools

\section{Introduction}

Human knowledge has always been known either as an individual phenomenon (information processing) or as a social phenomenon (in the context of where it happened). Since the cognitive revolution in the 60's, representations and representational theories have been the centre of attention. In this regards, knowledge is only known to be present in human minds. Training or teaching involves finding the most effective way to acquire access to this knowledge. Within the past 2 decades many educational psychologists and instructional designers have begun to move away from cognitive theories that emphasise on individualisation and the human mind. Instead, these researchers have come to accept that community and the nature of the underlying theories of cognition and meaning must be concentrated on and in particular emphasized on the 2 main sections of analysis being contextualised activity and participation (1). This learning approach involves a co-constructive process with a socio-cultural context system where meanings (culture) are shared among participants. In other words, the underlying factors as well as cultural and historical factors are considered as sections of analysis for individual cognitive processes (2). Additionally, instead of focusing on a series of individual operations it considers a operational system whereby participatory is important in this system. Participatory in this approach is both extensive and comprehensive such that individuals and social factors are considered and whereby it identifies socially-situated and culturally-mediated nature of learning (3). Sfard (1998) sees these changes in cognitive sciences and educational theories as a movement from the acquisition metaphor in learning towards participatory (4).

This paradigm is based in McGregor, acknowledgement of 3 types of constructivism: individual constructivism of Piaget, Vygotsky's social constructivism, and socio-cultural constructivism that goes beyond Vygotsky's ideas.

In the sociocultural constructivism paradigm, leaners build their knowledge through engaging in communities, such that they begin as legitimate peripheral participants and gradually by interacting with other more sophisticated members they will become active participates and may be out of legitimate participants label in the future (5). According to situated learning (6) and activity theory $(7,8)$ emphasis on the situations and context of learning, are categorized into sociocultural constructivism.

Moreover, technology is highly emphasised in learning environments of sociocultural constructivism. Here, technology is not just acknowledged as a medium and trans- 
fer of knowledge but is also considered as a tool for learning and a form of knowledge building paradigm. Jonassen views this learning paradigm change as a movement from "learning from computers" to "learning with computers". In this approach, the learner is known as the designer and the computer is acknowledged as a learning tool for the purpose of analysis and the organization of learners knowledge $(9,10)$.

Activity theory is a social psychology framework derived from 2 pillars of Soviet psychology theories including Vygotsky's cultural historical theory of psychology in the 1920 s and Marxist materialism in the 1930s.

Although, the activity theory, or in some cases referred to as the cultural historical activity theory (CHAT), can be used to design learning environments, in reality they are analysis tools for understanding activities of humans. In these theories, tools in cultural and social context are of high importance (11).

The origins of this idea was from Vygotsky, which was later changed and extended by fellow students from the same university including Leontev.

Vygotsky is different from his contemporaries such as Thorndike, Wundt, and Hull that believed there was a direct relation between the object (stimulus) and subject (responder) while Vygotsky maintained that all psychological activity is mediated by a third element. This third element is labeled as a tool or instrument. In general, tools are divided into 2 categories of material tools such as hammers or pencils and psychological tools like signs and symbols. As shown in Figure 1, Vygotsky uses a triangular scheme in order to express his approach and in which components of an activity are shown (1).

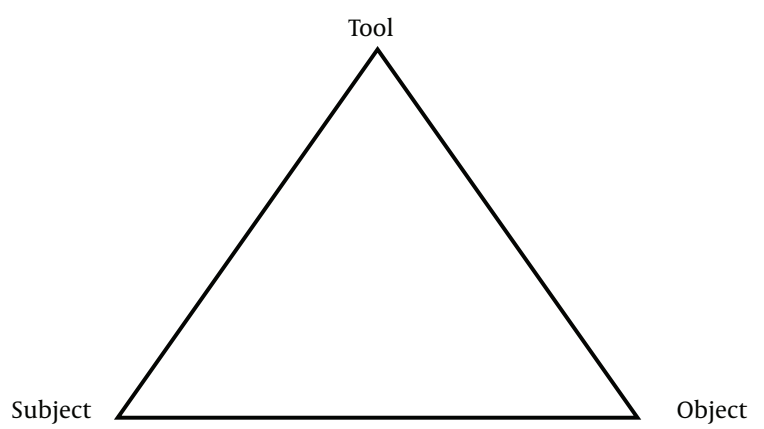

Figure 1. The Basic Schematic of Mediated Activity as Developed by Vygotsky (1)

Vygotsky's scheme is composed of the subject, object, and mediating tools. In this scheme, subject refers to the individual or individuals that want to do a particular activity. The object is the goal that is performed by the sub- ject, which directs the activity. Mediated tools include artefacts, signs, language, symbols, and so forth and are psychological tools through which people communicate (12). What Vygotsky mostly emphasised on was the fact that the design of the activity could not be dealt with separately. He believed that tools have a historical background and within history, humans have created tools and have used them and that knowledge in relation to them has a similar process to history and culture. It must be considered that although tools are useable whenever performing a particular activity, they are also created through activity (1).

Groups of Vygotsky's students, after his death, under the leadership of Leontiev, started to revise Vygotsky's theory. They criticised and provided revisions were based on 2 viewpoints: 1) Vygotsky's statements and ideas on activity was not completely developed and in this regards Leontiev provided an extended plan and focused on the fact that activity facilitated dialogue between the interior and exterior world and 2) Vygotsky emphasised highly on acknowledging individuals or an individual as Unit of Analysis and whereby in this case Leontiev and Engeström stressed on culture and history (12).

Leontiev was able to provide a clearer view of the meaning of activity as well as the nature of Collective learning. Unlike the past that emphasised on the subjects, he focused on the object's place in the concept of activity. In characterizing activity, Leontiev believed that there are differences between the immediate action and the larger overall activity system and proposed 3 hierarchical levelsoperation, action, and activity. An activity system can be thought of as having 3 hierarchical levels corresponding roughly to automatic, conscious, and cultural levels of behavior (from the bottom to the top), whereby operation at the automatic level is situated at the lowest level and then action and awareness are at the highest levels. As shown in Figure 2, activities are not static and are instead dynamic. They change and develop and whereby this development can occur either in a top-down or bottom-up manner (Figure 2) (7).

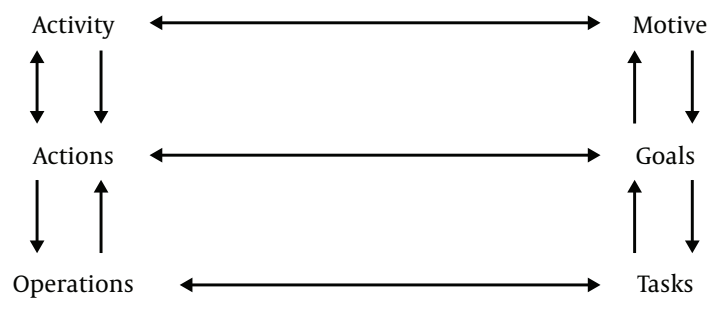

Figure 2. The Activity Hierarchy of Leontiev (7) 
Engeström, based on Leontiev's theory, proposed a triangular model and in effect extended Vygotsky's triangular scheme, with the difference that with the addition of components such as community, division of labour, and rules, the situation where learning takes place is more stressed upon.

As shown in Figure 3, it is clear that instrument or tools are mediators between subjects and objects, rules are mediators between subject and community, and finally division of labour mediates between community and object (8).

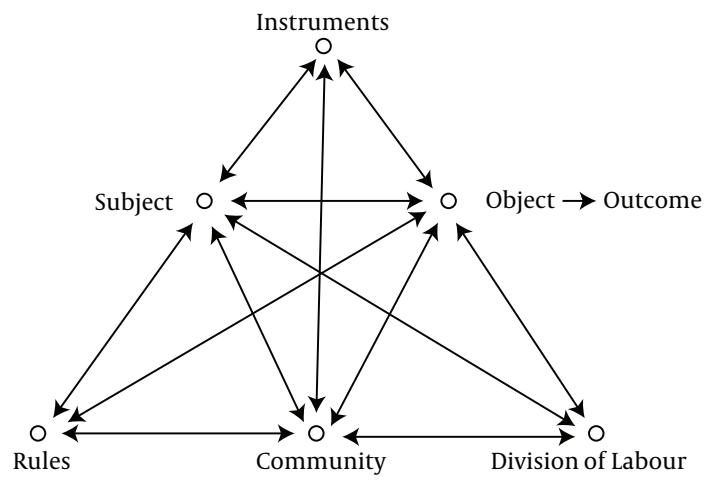

Figure 3. The Basic Schematic of an Activity System as Developed by Engestrom (8)

Although, Barab and his fellow researchers believed that activity theory is widely accepted in learning and education and the main applicability of activity theory can be seen within 2 categories of design and analysis. However, in general, activity theory is a tool for analysis (13) and uses a variety of components including human-computer interaction (14), information systems (15), designing user interfaces (16), communities of practice (17), and education (8).

Situated cognition or situated learning was first introduced by Jean Lave as a learning model within the community where the activity is situated in. In its simplest form, learning in situated learning occurs in the same context that it will be used in.

Situated learning has created an important change in physiological learning when comparing that community rather than individuals may be used as analysis tools. Situated learning is defined as a form of learning skills and knowledge in real world context. Therefore, situated learning encourages teachers such that by acknowledging that the learning environment is similar to the environment where learning is used, the percentage of transferring and acquisition of learning is increased (18).

Lave and Wenger view learning as an integral part of generative community of practice in the lived-in world.
Here generative implies that learning is an act of creation or co-creation. Social suggests that at least a portion of learning time occurs in partnership with others and where life in this universe involves real-world activities and settings that make learning more clearly useable and more transferable. For example, learning a foreign language can only be effective when learners have conversational practices as well as understanding the culture of the language they are learning, rather than through impractical grammar exercises (19).

Dynamic communities of practice are one of the main factors of this theory. Wenger maintains that this community is a group of individuals that have common concerns or agreements in relation to a particular topic. This community emphasises on the knowledge of a particular field and in which during this time they increase their expertise. Therefore, learning not only involves teachers and students but also other experts from schools, businesses, local communities, and also from the electronic world. In addition to this community, learning is deemed dynamic and its members may have different roles based on the learners needs. For example, a learner, in addition to being a leaner may also have other roles such as being a teacher or teaching assistant (19).

Legitimate peripheral participation is another main factor of this theory whereby learners begin as legitimate peripheral participants, do not have access to all resources, and gradually interact with professionals until they come to the stage that they can fully participate and become professionals themselves. In this regards, if newcomers directly observe skilled individuals they can have a deeper understanding and vice versa if individuals are distant or are in some manner separated from experts in their field of work and do not have access to tools and communities their knowledge will be limited.

Assessment in situated learning requires the understanding of the operations of individuals in different situations.

In learning environments, based on theories regarding socio-cultural constructivism, technology is emphasised. However, technology in this case is not just viewed as a medium or tool to transfer knowledge but is also acknowledged as a tool for learning and in some ways a form of building knowledge. In other words, learners are active individuals that through such tools can build their own knowledge and by engaging themselves and being active gain better learning results. In cognitive tools, traditional means of presenting knowledge is no longer used and rather than experts and educational designers only using these tools they are also made available to learners. Learners as designers use technology as a tool for analysing the world, accessing information, accessing and organis- 
ing their knowledge, and sharing their knowledge with others (10).

Cognitive tools are tools that enable learners through participation and manipulation to increase self-awareness and to develop their own arguments. The process of manipulation through a mind tool can occur either independently or through interactive dialogue. Faradanesh believes that cognitive tools are not only computer tools but that many computer tools can behave as mind tools in the best possible manner (20).

Theoretical foundations of cognitive tools can be found within constructivism and distributed cognition theories. In constructivism, individuals are active participants in meaningful activities such that their new knowledge is acquired and their understanding is enriched. In this approach factors such as knowledge building, being active, self-leadership, participation, and sharing knowledge based on the context, situation, and transferring information are emphasised as discussed in (21). Moreover, in considering the variety and wide range of cognitive tools they can enable learners to build their knowledge and to interact with others. In distributed cognition, processes including cognitive, understanding, learning, reasoning and memory are not limited to the minds of an individual. According to this theory, cognition is distributed between human minds, external cognitive tools, groups of individuals, and time and space where as learning can be achieved through cultural, social, and symbolical distribution between individuals and tools that they use (22).

Most contextual instructional design models and frameworks, in order to clarify teaching-learning process, are derived from educational theories and psychology of learning. Considering weakness in applying of sociocultural constructivism approaches and theories in the educational system in Iran, this study intends to answer two questions: What is the role of the community of practice in the design of learning environment based on socio-cultural approaches? and How should be analysed?

What are the components of social learning environment based on sociocultural approaches? Extract a contextual model along with workable examples that can be used by designers, educational experts, and teachers. In the following section a model shall be proposed through the use of qualitative content analysis.

\section{Methods}

The study was conducted in 2015. The method of this research is based upon qualitative content analysis. Mayring views this method as an approach of empirical, methodological controlled analysis of texts within their context of communication, following content analytical rules, and step by step models, without rash quantification (23). In this research deductive, content analysis is used, whereby it is generally used when there are different viewpoints on the research subject matter and when the aim of the research and previous tests or its development are in different contexts. The statistical population included documents, articles, posts, and reviews written that were found in some article banks in the English language such ELsevie , Google, and Springer with computer during 1991- 2014 (100 sources) related to the 3 theories of this study. The content of these resources were selected and analyzed using the purposive sampling method.

In qualitative content analysis, research initially begins with previous theories and codes and then the journals are extracted from the theories and research findings and before the analyses are defined (24). Figure 4 depicts this process where first the principal theories including activity, situational, and learning theories as well as cognitive tools for analysis, categories, and subcategories and finally coding and separating categories from sub-categories and a structured matrix is created. Then, once categorisation is once again performed, concepts are tested and finally a conceptual model is developed. In considering the importance of learners building artefacts and the importance of learners producing multimedia with different objectives for such as subjects including maths, science, programming, and others, this research will provide examples in regards to designing learning environment for the purpose of introducing high school children to designing and building multimedia. In addition, as previously mentioned, activity theory can be divided into design and production, which is used within this research for the purpose of analysing community.

\section{Results}

Categories that are in this study and are using qualitative content analysis of situated learning, activity theory and cognitive tools obtained in the Table 1 are provided

The combination of instructional design learning environments using the activity theory, situated learning and cognitive tools: According to the principles of situated learning, individuals are performing an activity within a particular field of knowledge and their activity, in a community, in such a manner that the individual must, from the very beginning, become familiar with their community that comprises of experts or skilled professionals in their area, such that they too can gain such expertise. Therefore, a situated learning environment should include the characteristics of elements, rules, objective tools, and should be a community of practice whereby the individual is supposed to be part of. In addition, in the theory of 
Preparation phase

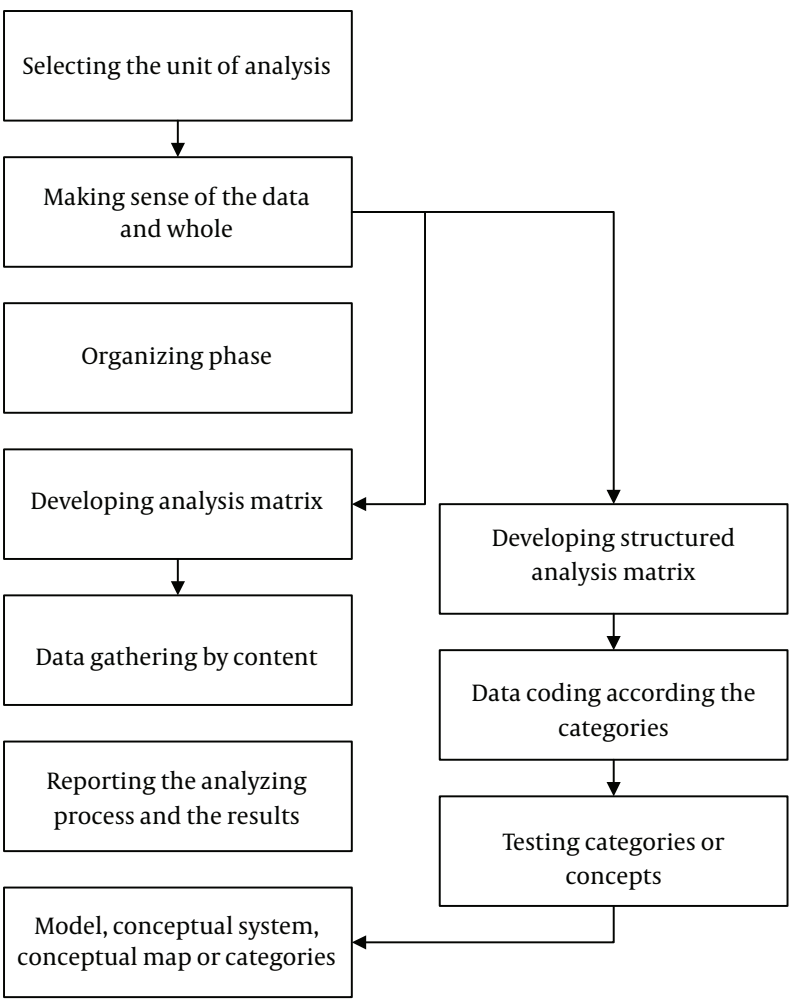

Figure 4. Preparation, Organizing and Resulting Phases in the Content Analysis Process (24)

situated learning, individuals need to be trained in such a manner that they can make use of their knowledge in real life situations. In other words, the learning environment is influenced by characteristics of the environments of both community and life.

Henceforth, in order to design a learning environment based on the theory of situated learning, there should be full recognition given to the community of the profession or special skill and in addition to using activities that have application in increasing acquired knowledge and skills to real-world situations. In this regards, the first step in the proposed model is designing face-to-face, online, or blended learning environments of community in which the subject and domains of knowledge are associated with.

After receiving information about the framework of community, designing learning environment should be started. According to the theories presented, the learning environment and three-factor such as tools, learner, and activity are closely related and are highly important. The learning environment can include factors such as presenting resources of information, modelling, coaching scaffolding, and changing the roles of learners whereby in return for the interaction between the three-factor tools, learning, and activity will be provided at every stage. Figure 5 shows a summary of this model.

1) Analyzing community of practice with activity theory: As described, analysis of the characteristics of community in situated learning theory is of great importance. For this purpose, the first step in the design of learning environments is the analysis of the community in question. As mentioned in learning theories, one of the most useful applications of the activity theory, is the analysis of different systems including community and where community as well as other communities or different system that includes a set of actions that occur with a specific purpose in a particular context and can be analysed using analytical tools activity theory.

As given in the examples of Table 1, if a learning course multimedia is required to be designed and produced thorough the use of technology or computer software or through the help of web-based instructions, experts from the species field should be interviewed such that the characteristics of the community in the online learning environment can be reflected. In this regards, the factors including objectives, subjects, tool, rules, community, division of labour operation, and action of Table 1 can be considered such that the activities of a community within a specific field can be analysed and the design of course can be presented.

After analysing the results, the community, design, and or teacher can, with a better insight, design their learning environment. Henceforth, learners can perform activities similar to professionals of the same field and gradually be part of the same community.

Although, analysing community can be complex, the teacher and or designer with the use of techniques such as interviews with members of community, considering the activities performed by the experts and Web pages of educational institutions in different academic fields (these institutions usually provide a list of outputs of learning activities within their graduate section) can gain necessary information of the community in question.

2) Designing learning environment: by reflecting the analysis that was performed in the previous stage, a learning environment can be designed that presents experiences within an environment similar to those experienced by experts of the same field. In other words, the analysis performed should be reflected in all sections of the design and in addition to this, in order to relate to real world situations, tangible and applicable activities must be used.

As mentioned in the beginning of this section, this 


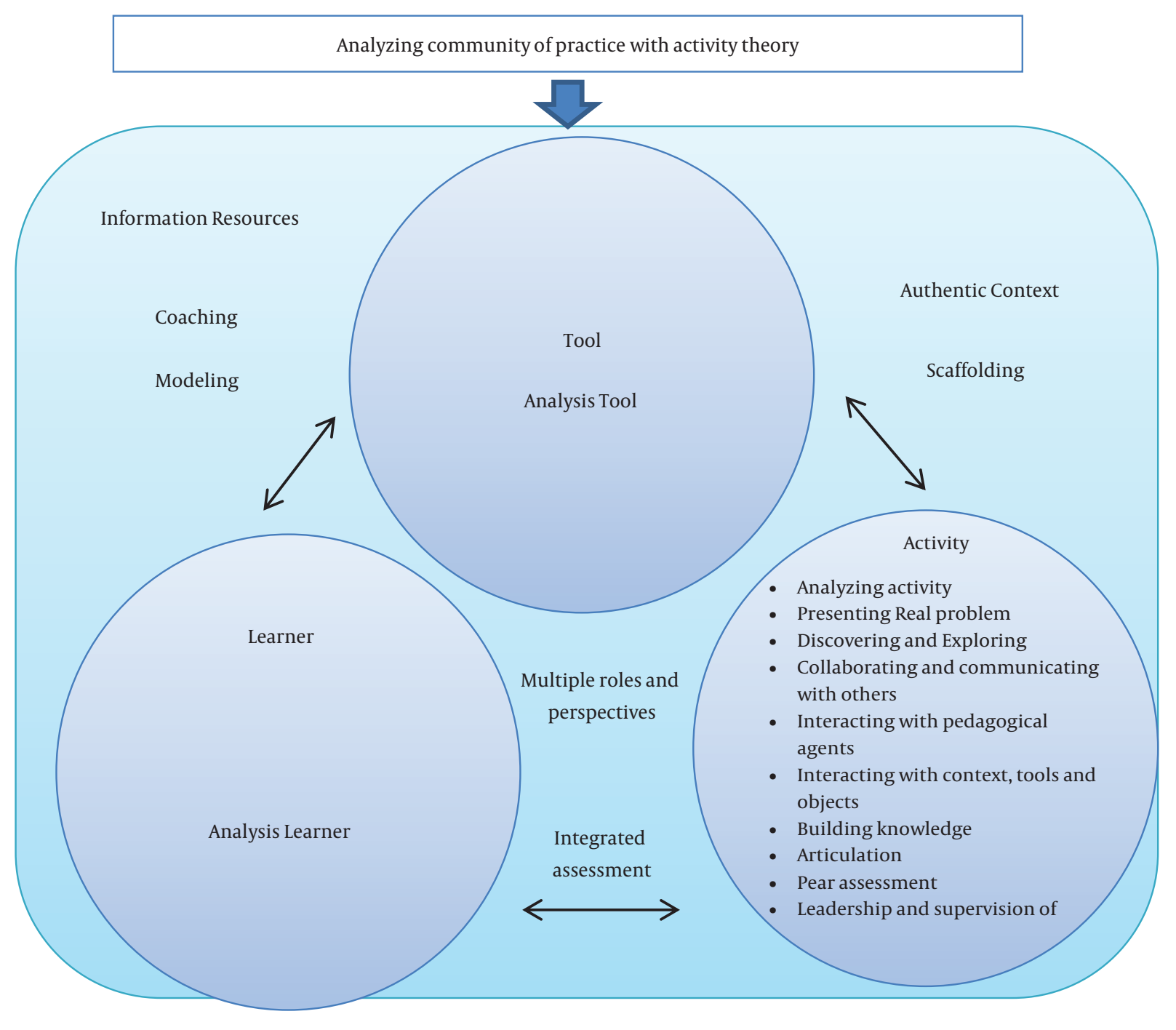

learning environment model consists of three-factors such as tool, learners, and activity and as a result of their integration they have supporting factors including modelling, information resource, coaching, and others similar to these, that will be presented by the given environment when felt necessary to support given activities. In the following, Learners analysis, Tools analysis, and Activity analysis as well as the supporting factors are described.

- Learner's analysis: Before starting the course, the learners required knowledge and skills must be identified. In addition, their talents and characteristic, experiences and background information, interests and technical skills must be examined and analysed.

- Analysis and design of learners' activity: Activity can be categorized by its cognitive, psychomotor, emotional, social levels and to offer special tools for each activity. Jansen (1994), Kim and Reeves (2007) present taxonomy of cognitive tools.

Presenting real problem: after analysing activity they must be presented. Presented issues and activities have to define real world activities

Discover and Explore: before commencing an opportunity is given to the learner to explore their learning environment, to recognize it, to find resources as well as the opportunity to act within their environment or to solve problems without participation or guidance. This can be enhanced through the use of virtual (online) environments or computer simulations. 
Participation and interaction with others: after the discovery of individuals, learners can participate with other people and with the formation of learning communities and directions from coaches they can work on specific issues.

Interaction with pedagogical agents: learners during an activity and at every stage of their learning with the aid of their coach or training agents or web-based educational software can communicate and receive relevant feedback.

Interaction with current subjects, objects, and tools: in each activity the leaners should be given the opportunity to ensure they gain the greatest benefit of learning from authentic fields and objects and from necessary tools.

Building knowledge and its experiences: Finally, the opportunity has been made available for learners through the use of available tools in an environment for building and developing knowledge.

Articulation: the opportunity has been made available for learners to discuss their experiences for each other and with their coach and through this manner learners can learn various skills such as cognitive, social, and metacognitive from each other.

Peer assessment: after the learners start their activities or when learners have sent reports to one another, there is an opportunity for them to judge and criticize each other's evaluations.

Leadership and supervising peers after becoming experts: after learners become experts they can become team leaders and henceforth will have reached a mastery level.

- Analysis and Design of Learning Tools: First, tools that can help specific learners and their special activities must be identified and a collection of these tools must be acquired and presented them at an appropriate time.

- Common factors that support activities, tools and learners

- Authentic context: in this stage, the analysis done in the previous stage for the identification of the community and required field of area the authentic context is designed similar to real world contexts.

- Information resources: resources made accessible to learners such that they can solve required issues. This resource can be presented in any form and is available when required.

- Access to expertise performance and modelling process: learners must have access to the performance of experts such to formulate a model from them. Modelling can range from simple to complex skills and activities. Modelling for cognitive activities are more complex and should include all mental and cognitive processes as well as details of tasks. Modelling should be done in authentic context to allow for easy transfer of learning. In technology based environments, the design through the use of videos, animations or instructional agents can show the various steps of doing a particular task as well as various activities

- Support for collaborative knowledge construction: In order to perform activities such as role play, building knowledge, and working with tools can be arranged such that individuals participate by engaging with one another.

- Learners' familiarity with multiple roles and perspectives: according to theories of situated learning; learners should be given the opportunity to explore different perspectives and roles. For example, in the form of role playing activities, learners in different roles and their activities can be examined and or to give them this opportunity such that after gaining a certain level of expertise, they gain an award or certificate and by changing roles give guidance and supervision to other peers and newcomers and or to use the benefits of environment.

- Coaching: through the use of training agents or selfteachers and coaches for directing and solving problems that learners may have as when needed.

- Scaffolding: by creating scaffolding to facilitate leaners to gain awareness of a skill or its application beyond their cognitive level.

- Assessment: by considering the models and theories of situated environments that have been presented, within such environments learners experience different roles at different levels in different groups with different activities and with different situations and therefore design should be examined in such a manner that learning is evaluated in all stages.

\section{Discussion and Conclusion}

Learning theories often involve general educational strategies that are used under specific design models and that have been previously defined as aid designers, educational experts, and teachers in designing better learning environments. In this paper, with emphasis and combination of sociocultural constructivism paradigm, with cognitive tools as well as theories including the activity theory and the situated learning theory, an instructional design model is proposed. The proposed model utilizes the benefits of the analysis systems to its fullest level and through practical examples; this efficient model based as well as being based on well-known theories is highly suitable and practical for teaching and learning specialists.

Although the theories within this model have their own specific characteristics, all 3 are influenced by sociocultural constructivism. In the mentioned approaches the unit of analysis of cognitive processes in the mentioned approaches on a specific subject and learning environment changes and the learning context in which learners are active in is of particular importance. In accordance to the 
qualitative analysis of relevant theories as in Table 1, the proposed model with factors such as analysis of society, tools, learning, activity, scaffolding, as well as coaching, authentic context, multiple roles and perspectives, and evaluation is illustrated within Figure 5.

The proposed model has 2 phases of society analysis and designing learning environments. Initially, the analysis of the learners' society will be carried out and whereby its results will be reflected in later phases of its design. Subsequently, in the second stage, being the design of the learning environment, components consisting of a three-factor tool, learning and activities must be considered. These 3 components have mutual communication through the use of several factors such as scaffolding, modelling, coaching and so forth and are supported accordingly. Notably, the proposed model has the capability of operating in all learning environments including face-toface, online, and blended environments.

\section{Footnotes}

Author's Contribution: Study concept and design: Maede Maleki and Hashem Fardanesh; analysis and interpretation of data: Maede Maleki and Hashem Fardanesh; drafting of the manuscript: Maede Maleki and Hashem Fardanesh; critical revision of the manuscript for important intellectual content: Maede Maleki and Fardanesh; qualitative analysis: Maede Maleki and Hashem Fardanesh.

\section{Conflict of Interest: None declared.}

\section{References}

1. Barab SA, Evans MA, Baek EO. Activity theory as a lens for characterizing the participatory unit. Handbook of research on educational communications and technology. 2.;2004.

2. Barab SA, Duffy T. From practice fields to communities of practice. Theor Foundat Learn Environ. 2000;1(1):25-55.

3. Westberry NC. An activity theory analysis of social epistemologies within tertiary-level eLearning environments. University of Waikato; 2009.

4. Sfard A. On two metaphors for learning and the dangers of choosing just one. Educ Res. 1998;27(2):4-13.

5. McGregor D. Developing thinking; developing learning. McGraw-Hill Education (UK); 2007.

6. Lave J. Cognition in practice: Mind, mathematics and culture in everyday life. Cambridge University Press; 1988.
7. Leont'ev AN. Activity, consciousness, and personality. Englewood Cliffs: Prentice-Hall; 1978.

8. EngestrY. Learning by expanding: An activity-theoretical approach to developmental research. Helsinki, Finland: Orienta-Konultit; 1987.

9. Jonassen DH, Carr C, Yueh HP. Computers as mindtools for engaging learners in critical thinking. Tech Trends. 1998;43(2):24-32. doi: $10.1007 / \mathrm{bf02818172}$

10. Jonassen DH. Technology as cognitive tools: Learners as designers. IT Forum Paper. 1994;1:67-80.

11. DeVane B, Squire KD.10 Activity Theory in the Learning Technologies. Theor Foundat Learn Environ. 2012:242.

12. Engestrom Y. Innovative learning in work teams: Analyzing cycles of knowledge creation in practice. Perspect Activity Theory. 1999:377-404

13. Abdullah Z. Activity Theory as Analytical Tool: A Case Study of Developing Student Teachers' Creativity in Design. Proc Soc Behav Sci. 2014;131:70-84.

14. Kuutti K. Activity theory as a potential framework for humancomputer interaction research. Context and consciousness: Activity theory and human-computer interaction. ;1996.

15. Bodker A, Rasmussen TB, Christensen MB. The absorption of chlortetracycline following transscrotal instillation for the treatment of primary hydrocele testis. J Urol. 1991;145(4):792-4. [PubMed: 2005703].

16. Bodker S. Through the interface-A human activity approach to user interface design. DAIMI Rep Series. 1987;16(224).

17. Engestrom Y. Developmental studies of work as a testbench of activity theory: The case of primary care medical practice. Understanding practice: Perspectives on activity and context. ;1993.

18. Collins A. Cognitive apprenticeship and instructional technology. Educational values and cognitive instruction: Implications for reform. $1991: 121-38$.

19. Lave J, Wenger E. Situated learning: Legitimate peripheral participation. Cambridge university press; 1991.

20. Fardanesh $M$, White $C$. Missed lung cancer on chest radiography and computed tomography. Semin Ultrasound CT MR. 2012;33(4):280-7. doi: 10.1053/j.sult.2012.01.006. [PubMed: 22824118].

21. Kim B, Reeves TC. Reframing research on learning with technology: In search of the meaning of cognitive tools. Instruct Sci. 2007;35(3):20756.

22. Dieterle E. Multi-user virtual environments for teaching and learning. Encyclopedia of Multimedia Technology and Networking, Second Edition. IGI Global; 2009.

23. Mayring P. Qualitative content analysis. Qual Soc Res. 2000;1(2).

24. Elo S, Kyngas $H$. The qualitative content analysis process. J Adv Nurs. 2008;62(1):107-15. doi: 10.1111/j.1365-2648.2007.04569.x. [PubMed 18352969].

25. Jonassen DH, Rohrer-Murphy L. Activity theory as a framework for designing constructivist learning environments. Educ Technol Res Dev. 1999;47(1):61-79.

26. Law ELC, Sun X. Evaluating user experience of adaptive digital educational games with Activity Theory. Int J Human Comput Stud. 2012;70(7):478-97.

27. Goldberg R, Dennen P. Long-term outcomes of acute kidney injury. Adv Chronic Kidney Dis. 2008;15(3):297-307. doi: 10.1053/j.ackd.2008.04.009. [PubMed: 18565480]. 
Table 1. Categories of the Components of the Conceptual Model in Situated Learning, Activity Theory and Cognitive Tools

\begin{tabular}{|c|c|c|c|c|}
\hline & Definition & Example & Coding rules & Theory \\
\hline Mediating tool & $\begin{array}{l}\text { Mediated tools include artefacts, signs, } \\
\text { languages, symbols and so forth and are } \\
\text { psychological tools through which people } \\
\text { communicating, experience and building } \\
\text { reality (25). }\end{array}$ & $\begin{array}{l}\text { Students using multimedia software such } \\
\text { as AutoPlay and Builder to build } \\
\text { multimedia }\end{array}$ & $\begin{array}{l}\text { Identifying Cognitive tools suitable for } \\
\text { building multimedia }\end{array}$ & Activity Theory \\
\hline object & $\begin{array}{l}\text { The object is the goal that is identified by } \\
\text { the subject and to which the activity is } \\
\text { directed to (25). }\end{array}$ & Producing instructional multimedia & $\begin{array}{l}\text { The object is of importance as it identifies } \\
\text { the activity }\end{array}$ & Activity Theory \\
\hline Subject & $\begin{array}{l}\text { The subject is an individual or individuals } \\
\text { that want to perform their activity (25). }\end{array}$ & $\begin{array}{l}\text { Although students are the main subjects } \\
\text { but by considering the use of activity } \\
\text { theory for analysis, all the individuals in } \\
\text { organisations and private companies } \\
\text { produce instructional multimedia } \\
\text { content (community of practice) }\end{array}$ & $\begin{array}{l}\text { Importance of analysis of learners or } \\
\text { individuals from a society }\end{array}$ & $\begin{array}{l}\text { Activity theory, situated leaning theory } \\
\text { and cognitive tools }\end{array}$ \\
\hline Division of labour & $\begin{array}{l}\text { How tasks, power and situations within a } \\
\text { community are distributed (26). }\end{array}$ & $\begin{array}{l}\text { Individuals that are part of the } \\
\text { multimedia production team; from } \\
\text { graphics, animation, to photographers } \\
\text { and cameramen }\end{array}$ & $\begin{array}{l}\text { Importance of identifying different } \\
\text { expertise in community }\end{array}$ & Activity \\
\hline Community & $\begin{array}{l}\text { One or multiple individuals that have a } \\
\text { goal or common goals }(26)\end{array}$ & $\begin{array}{l}\text { Community of teachers, Community of } \\
\text { multimedia }\end{array}$ & Importance of context & Activity \\
\hline Output & $\begin{array}{l}\text { An idea, a situation status or a negative or } \\
\text { positive feedback ( } 26)\end{array}$ & Learning to produce multimedia & Importance of output & Activity \\
\hline Rule & $\begin{array}{l}\text { Existing rules and interactions within an } \\
\text { activity (26) }\end{array}$ & Intellectual property rights, $\ldots$ & $\begin{array}{l}\text { Importance of learning existing rules } \\
\text { within an activity }\end{array}$ & Activity \\
\hline Learner as a designer & $\begin{array}{l}\text { Providing learners the opportunity to } \\
\text { represent knowledge through the use of } \\
\text { cognitive tools (10) }\end{array}$ & $\begin{array}{l}\text { Building a multimedia project in the field } \\
\text { of science }\end{array}$ & Learner is active in building knowledge & Situated learning cognitive tools \\
\hline Modelling & $\begin{array}{l}\text { Modelling can range from simple to } \\
\text { complex skills and activities. Modelling } \\
\text { for cognitive activities is a more complex } \\
\text { process and should include mental, } \\
\text { cognitive processes and details of the } \\
\text { work in process (10) }\end{array}$ & Stages of audio and video production & $\begin{array}{l}\text { Show details of a process, a phenomenon, } \\
\text {... }\end{array}$ & Situated learning \\
\hline Scaffolding & $\begin{array}{l}\text { A form of aid for learners from teachers or } \\
\text { from other students for the purpose of } \\
\text { supporting learning. In this scenario the } \\
\text { teacher helps the learner to master a task } \\
\text { or concept that initially they had } \\
\text { problems understanding (27). }\end{array}$ & $\begin{array}{l}\text { With the scaffolding the learners have the } \\
\text { opportunity to learn a skill or gain } \\
\text { knowledge on how to use them, beyond } \\
\text { the cognitive level. }\end{array}$ & $\begin{array}{l}\text { Aiding the learner beyond their learning } \\
\text { capabilities }\end{array}$ & Situated learning \\
\hline Coaching & $\begin{array}{l}\text { The use of pedagogical agents or specific } \\
\text { avatars for training and guidance to } \\
\text { learners' problems, as when required (27). }\end{array}$ & & Supporting learners & Situated Learning \\
\hline Dynamic learning communities & $\begin{array}{l}\text { Learners may take on different roles } \\
\text { depending on their requirements. For } \\
\text { example, an individual in addition to } \\
\text { being a learner can at the same time be a } \\
\text { teacher or coach. }\end{array}$ & $\begin{array}{l}\text { Taking the role of a video producer/ editor } \\
\text { within a task or taking the role of a film } \\
\text { producer/ editor within other tasks }\end{array}$ & Dynamic role of learners within a society. & Situated Learning \\
\hline Legitimate peripheral participation & $\begin{array}{l}\text { Initially learners are considered as } \\
\text { legitimate peripheral participants and do } \\
\text { not have access to all resources and } \\
\text { gradually they interact with other } \\
\text { members with more expertise to be able to } \\
\text { gain full participation and become a } \\
\text { legitimate participant. }\end{array}$ & $\begin{array}{l}\text { Newcomers become familiar with tasks or } \\
\text { that have restrictive roles and gradually } \\
\text { tasks become more complicated and they } \\
\text { are linked with experts in building } \\
\text { multimedia }\end{array}$ & Gradual participation from learner & Situated Learning \\
\hline Building knowledge tool & $\begin{array}{l}\text { Learner as a designer by using technology } \\
\text { as a tool to analyse the world, access } \\
\text { information, manipulate and organize } \\
\text { their own knowledge and by presenting } \\
\text { all that they know to others (10) }\end{array}$ & $\begin{array}{l}\text { Use of concept mapping tools, modelling, } \\
\text { production, etc. in order to build a } \\
\text { curriculum and in general to build } \\
\text { educational multimedia }\end{array}$ & $\begin{array}{l}\text { Importance of building an artefact in } \\
\text { learning }\end{array}$ & Cognitive tools \\
\hline Community of practice & $\begin{array}{l}\text { Communities of Practice are groups of } \\
\text { people that are in the same industry (e.g. } \\
\text { Art) or profession. These communities } \\
\text { focus on a range of knowledge and } \\
\text { through the process of sharing knowledge } \\
\text { and learning through the experience of } \\
\text { other members of the group and over time } \\
\text { they increase their expertise within a } \\
\text { particular area (22) }\end{array}$ & $\begin{array}{l}\text { Taking into account a group of people that } \\
\text { work in a particular field. For example, in } \\
\text { building multimedia all programmers } \\
\text { that are content producers who produce } \\
\text { multimedia are part of a society. }\end{array}$ & $\begin{array}{l}\text { The importance of identifying people who } \\
\text { are going to join learners in the future }\end{array}$ & Situated Learning \\
\hline Authentic learning & $\begin{array}{l}\text { Learning in an environment similar to the } \\
\text { lives of students and society }\end{array}$ & $\begin{array}{l}\text { It results from learners expect in the form } \\
\text { of a multimedia company that engaged in } \\
\text { design to any real responsibility }\end{array}$ & Focusing on authentic activities & Situated Learning \\
\hline Assessment & $\begin{array}{l}\text { Assessment in situated learning requires a } \\
\text { combined assessment to identify the } \\
\text { people in different situations and } \\
\text { especially putting the learner in real world } \\
\text { situations. }\end{array}$ & $\begin{array}{l}\text { Identification of learner performance in } \\
\text { order to design multimedia, produce and } \\
\text { edit video, sound and. }\end{array}$ & Importance of situation assessment & Situated Learning \\
\hline Operations & $\begin{array}{l}\text { Operations in the context of the activity } \\
\text { are influenced under current conditions. }\end{array}$ & $\begin{array}{l}\text { Producing and editing images, acquiring } \\
\text { video clips, combing audio visual } \\
\text { resources }\end{array}$ & Focus on component of activity & Activity Theory \\
\hline Action & $\begin{array}{l}\text { Sets of operation constitute action and } \\
\text { action is affected by goal and its collection } \\
\text { composes an activity. }\end{array}$ & $\begin{array}{l}\text { Set of actions that are needed in order to } \\
\text { produce images. Sets of actions that are } \\
\text { desired in order to make a video clip. }\end{array}$ & Focus on component of activity & Activity Theory \\
\hline
\end{tabular}

